BMJ Paediatrics Open

\title{
Impact of COVID-19 on the diagnosis, assessment and management of children with inflammatory bowel disease in the UK: implications for practice
}

\author{
Abbie Maclean (D) , ${ }^{1}$ James J Ashton, ${ }^{2,3}$ Vikki Garrick, ${ }^{4}$ R Mark Beattie (D) , ${ }^{2}$ \\ Richard Hansen ${ }^{4}$
}

To cite: Maclean A, Ashton JJ, Garrick V, et al. Impact of COVID-19 on the diagnosis, assessment and management of children with inflammatory bowel disease in the UK: implications for practice. BMJ Paediatrics Open 2020;4:e000786. doi:10.1136/ bmjpo-2020-000786

AM and JJA contributed equally.

Received 1 July 2020

Revised 7 September 2020

Accepted 27 September 2020

Check for updates

C) Author(s) (or their employer(s)) 2020. Re-use permitted under CC BY-NC. No commercial re-use. See rights and permissions. Published by BMJ.

${ }^{1}$ School of Medicine, Dentistry and Nursing, University of Glasgow College of Medical, Veterinary and Life Sciences, Glasgow, UK

${ }^{2}$ Department of Paediatric Gastroenterology, Southampton Children's Hospital,

Southampton, UK

${ }^{3}$ Department of Human Genetics and Genomic Medicine, University of Southampton, Southampton, UK

${ }^{4}$ Department of Paediatric Gastroenterology, Hepatology and Nutrition, Royal Hospital for Children, Glasgow, UK

Correspondence to Dr Richard Hansen; richard. hansen@glasgow.ac.uk

\section{ABSTRACT}

The assessment and management of patients with known, or suspected, paediatric inflammatory bowel disease (PIBD) has been hugely impacted by the COVID-19 pandemic. Although current evidence of the impact of COVID-19 infection in children with PIBD has provided a degree of reassurance, there continues to be the potential for significant secondary harm caused by the changes to normal working practices and reorganisation of services. Disruption to the normal running of diagnostic and assessment procedures, such as endoscopy, has resulted in the potential for secondary harm to patients including delayed diagnosis and delay in treatment. Difficult management decisions have been made in order to minimise COVID-19 risk for this patient group while avoiding harm. Initiating and continuing immunosuppressive and biological therapies in the absence of normal surveillance and diagnostic procedures have posed many challenges.

Despite this, changes to working practices, including virtual clinic appointments, home faecal calprotectin testing kits and continued intensive support from clinical nurse specialists and other members of the multidisciplinary team, have resulted in patients still receiving a high standard of care, with those who require face-to-face intervention being highlighted.

These changes have the potential to revolutionise the way in which patients receive routine care in the future, with the inclusion of telemedicine increasingly attractive for stable patients. There is also the need to use lessons learnt from this pandemic to plan for a possible second wave, or future pandemics as well as implementing some permanent changes to normal working practices. In this review, we describe the diagnosis, management and direct impact of COVID-19 in paediatric patients with IBD. We summarise the guidance and describe the implemented changes, evolving evidence and the implications of this virus on paediatric patients with IBD and working practices.

\section{BACKGROUND}

The prevalence of paediatric inflammatory bowel disease (IBD) in the UK is approximately $0.05 \%$, with an estimated incidence of $10-12 / 100000$ year. $^{2}$ The coronavirus
(SARS-CoV-2) global pandemic has had a significant impact on all aspects of healthcare, leading to profound changes in working practices across all specialties. This resulted in very significant changes over a short period of time for services to be able to continue to deliver the highest standard of care to those who needed it. This occurred during a period of uncertainty with limited and slowly emerging evidence subsequently impacting how these changes were made. For children with IBD, there were and continue to be significant alterations to the diagnostic pathway, assessment and monitoring of disease, including, for example, the increased use of virtual management and reduced access to diagnostic and surveillance endoscopy.

The measures taken to protect this vulnerable patient group were enacted in order to protect from both the harm posed by the virus itself and the potential for secondary harm from service changes and access to healthcare with a high risk of secondary morbidity. During the months of lockdown in the UK, diagnostic and monitoring investigations for IBD, which were normally widely available, were largely reserved for emergency use only. ${ }^{3}$ There continue to be changes to these normal working practices as the UK emerges from lockdown phases. Figure 1 represents a timeline of key events during the COVID-19 pandemic within the UK.

As the prevalence of the virus reduced in the community, our understanding of its limited impact on paediatric patients was better understood. ${ }^{4}$ Reassuringly, the emerging evidence base from across the world has shown that IBD in children is not a risk factor for the development of severe infection with SARS-CoV-2. ${ }^{5}$ This is similar in adults. ${ }^{6}$ The Surveillance Epidemiology of Coronavirus Under Research Exclusion (SECURE)-IBD 
Timeline of events in the UK during the COVID-19 pandemic (Dec 2019-Sept 2020).

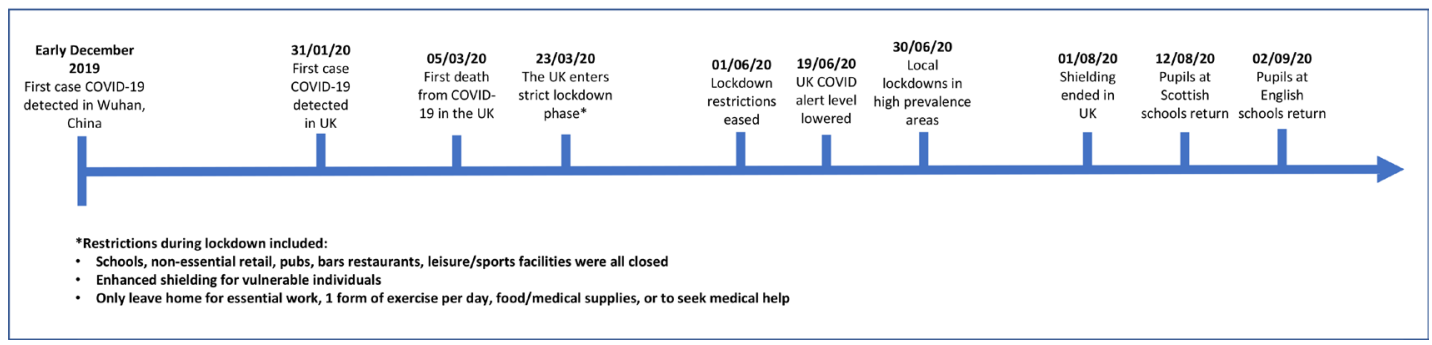

Figure 1 Timeline of major UK events in relation to the COVID-19 pandemic, December 2019-September 2021.

database has reported a total of 174 cases of COVID-19 in under 20-year olds worldwide. So far, only one of these cases required intensive care unit admission and ventilation and none have died. ${ }^{7}$ Another study of eight children with IBD who contracted SARS-CoV-2 has been reported by the Paediatric IBD Porto group of European Society of Paediatric Gastroenterology, Hepatology and Nutrition (ESPGHAN). All of these cases had mild symptoms, even where IBD treatment with immunomodulators and/or biologics was present. ${ }^{56}$ This evidence can provide some degree of reassurance for members of the paediatric multidisciplinary team (MDT) and patients with IBD alike, however, this must be interpreted with some caution as we await more data and potential developments in this evolving global pandemic.

This review aims to address the current impact of the COVID-19 pandemic on the diagnosis, assessment and management of paediatric IBD after rapid changes made during a period of uncertainty and with evidence of the impact of these changes emerging slowly thereafter. We suggest strategies to minimise harm and disruption to patients caused by the direct and indirect impacts of COVID-19, while operating within ongoing restrictions.

\section{Diagnosis of paediatric IBD}

Prior to recent changes, the international consensus for diagnosing IBD in children with appropriate symptoms, signs or supportive laboratory investigations was based on the revised Porto criteria, ${ }^{8}$ a combination of upper and lower gastrointestinal endoscopy with small bowel imaging - usually by MRI. The pathway to diagnosis for an individual patient would often involve review from general then specialist clinicians, preliminary investigations including blood tests and faecal calprotectin (FC), then referral to a specialist unit for further assessment and investigation, including endoscopy under general anaesthetic. Endoscopic assessment, as per revised Porto, allows the visualisation of the oesophagus, stomach, duodenum, ileum and colon, enabling a robust description of the location and extent of macroscopic disease (phenotype) while allowing tissue sampling for histological confirmation of disease and formal diagnostic classification. Phenotype impacts therapeutic options, with limited rectal disease being amenable to topical enema therapy and more extensive disease prompting consideration of early treatment escalation. The role of endoscopy in the initial diagnosis and in guiding treatment decisions in paediatric IBD is therefore fundamental.

\section{Investigations for paediatric IBD in the COVID-19 era}

Due to the restructuring of services as a result of COVID19, clinical examination, laboratory testing, endoscopic and radiological tests were all the more difficult to access. ${ }^{3}$ More specifically FC testing (which deals directly with stool samples) may have caused unnecessary viral exposure to healthcare and laboratory staff and, consequently, availability of this test was temporarily affected in a variable manner across the UK. ${ }^{9}$ Furthermore, face-to-face clinic appointments and physical examinations involve patient travel, interaction with multiple healthcare staff and ultimately increased risk of viral transmission, even where appropriate public health measures have been implemented, and so were extremely limited and remain limited at present.

Delayed diagnosis of paediatric IBD is associated with poorer outcomes and higher risks of surgery. ${ }^{10}$ These risks must be carefully weighed up with the potential risk posed by COVID-19 to both patients and healthcare staff. Furthermore, decisions to defer or expedite diagnostic investigations, particularly endoscopy, are extremely difficult and require multidisciplinary discussion and expertise, informed by current evolving data and evidence.

\section{Impact of COVID-19 on the referral pathway}

Paediatric IBD management is through referral networks across the UK. These pathways are key to implementing safe and timely referrals, alongside continued care. At the peak of the pandemic in the UK, there was reduced access to baseline tests, such as $\mathrm{FC}^{11}$ and subsequently onward referral to gastroenterology, and acceptance/prioritisation of referrals without objective markers suggesting IBD may have been delayed. The impact of this period on diagnosis and disease progression will require assessment once diagnostic catch-up is complete and all cases have sufficient follow-up data to look at outcomes.

\section{Guidance on the use of endoscopy}

The ESPGHAN published guidance on the use of endoscopy in April 2020, at an early stage of the COVID-19 pandemic in Europe. This guidance stated that 'all endoscopy except emergency and essential procedures 
should stop immediately'. ${ }^{12}$ This was in keeping with the virtual cessation of endoscopy in adult practice. ${ }^{13}$

The British Society of Gastroenterology and Joint Advisory Group (BSG-JAG) released a statement on 3 April 2020, which stated that all endoscopic disease assessments for IBD, surveillance endoscopies (IBD) and all symptomatic routine endoscopy referrals should be deferred until further notice. This was in line with UK government advice "to reduce any non-essential exposure to the COVID-19 virus and to take all reasonable measures to limit its spread'. ${ }^{13}$ The BSG published new guidance on 28 August 2020 that outlines specific COVID-19 infection prevention strategies within endoscopy units across the UK. The guidance recommends routine screening of patents 3-7 days prior to endoscopy, with COVID-19 testing occurring 1-3 days prior to the procedure. Additional self-isolation for 7-14 days prior to the procedure is not needed. In centres not performing routine COVID-19 testing, patients should self-isolate for 14 days prior to the procedure. This guidance allows for more endoscopic procedures to take place where risk stratification and testing are implemented. ${ }^{14}$

SARS-CoV-2 is mainly spread through droplets that enter the respiratory tract, however, viral RNA can also be found within stool, ${ }^{15}$ though whether this remains infectious is subject to ongoing research and is not yet clear. To date, a single case report has determined that live viruses can be present in the stool of a patient with severe COVID-19. ${ }^{16}$

Upper gastrointestinal endoscopic procedures are 'aerosol-generating', increasing the chance of respiratory droplet viral transmission to healthcare staff, something amplified by the prevalent use of general anaesthetic for endoscopies in paediatric practice. Whether lower gastrointestinal endoscopy poses a risk for transmission remains uncertain but this is not in itself currently deemed 'aerosol-generating'. ${ }^{15}$

Guidance published by BSG-JAG and ESPGHAN was used by clinicians to aid their decisions to either defer or initiate diagnostic investigations among uncertain evidence at the peak of the pandemic. This may have meant that patients with severe symptoms and high biomarkers were brought in for an endoscopy, whereas those with milder symptoms and borderline markers were deferred indefinitely or treated empirically. ${ }^{15}$

\section{Personal protective equipment requirements}

Guidance from BSG states that if a patient has been asymptomatic, tested negative in the preceding 48-72 hours and has no history of potential contact/exposure to infection, then standard personal protective equipment (PPE) can be justified. Those who do not meet these criteria should be carefully considered and deferred where possible. Enhanced PPE includes the use of double gloves and an FFP-3 mask and should be worn in the case of an essential or an emergency procedure, and where possible, this should take place in a separate location to those in the low-risk category. ${ }^{14}$ The guidance includes increased cleaning and, therefore, increases delays between cases in theatre. Careful selection of patients is, therefore, crucial to protect patients, staff and the PPE supply chain. ${ }^{14} 17$ As the evidence base improves with time, this guidance is likely to evolve to further maximise access to endoscopy in both a safe and timely manner while protecting patients and staff.

\section{Management of paediatric IBD}

Facilitating safe and holistic management of known patients with IBD has proved challenging. Services have relied on virtual infrastructure and initial uncertainty among healthcare professionals and patients/families was unavoidable.

\section{Immunosuppressive therapies and COVID-19}

Data from SECURE-IBD ${ }^{7}$ and adult cohorts ${ }^{18}$ suggest that the risk from IBD therapies is limited, with steroids conferring the highest risk. Paediatric patients were largely unaffected by COVID-19, with only 29 reported cases, of which 3 were hospitalised and none required ventilation or intensive care. ${ }^{19}$ By stopping medications, patients can potentiate disease flares that are associated with increased immunocompromise, potential exposure to high-dose steroids, increased infection risk, the need for hospitalisation and intervention. ${ }^{2021}$ There has understandably been a significant amount of anxiety among clinicians, patients and their families; however, children should continue their medications as normal. ${ }^{22}$

Recent expert guidance on the management of acute severe colitis in adults, and subsequently in children, largely supports the continuation of existing therapeutic approaches, including intravenous steroids and escalation to infliximab as appropriate. ${ }^{23} 24$

\section{Facilitating and monitoring ongoing maintenance therapy}

Monoclonal infusion services were reorganised as a priority to accommodate social distancing, limit patient journeys and minimise hospital exposure. This was done by moving these services to 'cold' areas. The focus on providing these services was clear from the start and allowed therapy to continue as required with minimal disruption. ${ }^{25}$

Thiopurines, including azathioprine and mercaptopurine, are used in paediatric IBD to maintain disease remission. These drugs have a significant side effect profile, so robust blood monitoring is necessary. ${ }^{26}$ During the COVID-19 era, the services to provide these blood tests were reorganised to allow for social distancing, with many patients still attending specialist centres, or in some cases, their local general practitioner (GP).$^{25}$ This required extensive planning across each network to ensure these services remained in place and patients on long-term treatments were kept safe.

Decision making for patients with IBD often uses endoscopic assessment, both with a view to escalation and in the assessment of response to therapy. Cessation of endoscopy during lockdown may have prevented adequate 
assessment and escalation for patients, with downstream effects not yet felt. The backlog of patients requiring routine endoscopic assessment is a vital consideration in recovery planning.

\section{Role of the MDT}

Paediatric IBD MDTs must carefully weigh up the risks of initiating treatments against the perceived benefits while doing so with reduced endoscopic capacity and so less diagnostic/phenotypic fidelity. Initiating new therapies during the COVID-19 era may therefore prove more difficult. It has become increasingly evident that continued expertise and intensive support from the IBD nursing team is fundamental to supporting patients and families during the pandemic, particularly because these professionals act as a lead point of contact and so receive the majority of queries/concerns from patients and families during a time of profound uncertainty. Allied health professionals, including psychology and dietetics, have continued to support patients and clinicians during the pandemic. These services have largely become virtual, with specific patients being reviewed face to face. ${ }^{27}$

\section{Changes to clinic appointments}

Many outpatient clinic appointments for new or follow-up patients have been switched to web-based consultations or telephone appointments. Importantly, this has happened rapidly and without significant infrastructure investment, staff retraining or job plan consideration. This has however facilitated social distancing, helped minimise the risk of infection for patients and staff and has allowed clinical care to continue with regular intervals and contact. A plan for any additional information needed (bloods or FC) can be arranged during such appointments while attendance at physical clinics has largely been reserved for acutely unwell patients, limiting patient numbers and allowing these reviews to be supported in line with established COVID-19 protocols in each National Health Service (NHS) trust area. Switching to virtual consultations has facilitated continued contact and has been well received by most patients and medical professionals. ${ }^{28} 29$ It has meant that there was no need to stop follow-up completely. Contact points, usually in the form of the IBD nurse team email/telephone advice line, must continue to be made available to patients and their families as a priority service provision. ${ }^{25}$ These services are commonly used to deliver rescue advice to patients experiencing disease flares or increased symptoms. In addition to providing monitoring advice, they also provide a conduit for rapid review and treatment. ${ }^{25}$

\section{Self-monitoring of disease activity: home FC testing}

FC is a useful marker of intestinal inflammation and has been shown to correlate well with endoscopic inflammation in IBD. ${ }^{11}$ Normally, FC testing is carried out as an ELISA test, which is considered the gold-standard method. ${ }^{30}$ This must be done in a laboratory setting, which is a potentially high risk for the transmission of
SARS-CoV-2 virus ${ }^{25}$ (involving stools) and so has been less widely available in many areas due to risk assessments or restructuring within hospital laboratory services. Home FC testing kits have been used as a substitute for some paediatric patients with IBD during this time. These kits have been tested in a number of trials comparing their results with the ELISA test with promising outcomes. One study of 221 patients with IBD found the CalproSmart test to have a moderate yet clinically relevant agreement with the ELISA test, with a sensitivity of $82 \%$ and specificity of $85 \% .{ }^{30}$ Further studies have suggested that the home IBDoc testing kits agree with ELISA tests at FC levels below $500 \mu \mathrm{g} / \mathrm{g} .{ }^{31}$

Home testing kits have been used in a specific cohort of patients to allow for surveillance at home, monitoring of treatment responses and (in combination with laboratory FC testing) flare detection requiring treatment escalation. An investigation into the feasibility of home FC testing concluded that $80 \%$ of parents felt this method would improve disease management, however, the practicality of using them was difficult for over half. ${ }^{32}$ This method of testing allows for greater patient empowerment with reduced embarrassment, especially for adolescents, perhaps leading to better compliance. The technology also allows smartphone apps to communicate results directly and immediately to the patient's MDTs, increasing efficiency and potentially also the speed of clinical reaction to elevated results. Coordinating the distribution of kits, providing support/education on their use and integrating their results into the clinical record and MDT forum are crucial roles that need specific thought prior to the use of such kits in practice. Despite the administrative nature of these tasks, many of these roles will naturally fall into the IBD nursing service but this is likely to already be under considerable pressure from other service alterations and pressures during a period of considerable flux.

\section{Moving into the 'recovery phases'}

As we move forward in our clinical response to COVID19 , the guidance surrounding the use of endoscopy is changing and will continue to evolve. ${ }^{33}$ Following the suspension of all but emergency and essential procedures, an early 'recovery phase' was implemented in the UK on 30 April 2020. In the context of paediatric IBD, this phase allowed for some new diagnostic and assessment endoscopies to take place, where clinical management will be influenced. Despite this, access to endoscopy remains variable and requires careful senior decision making, with reorganisation of services and staff, PPE considerations and patient screening all requiring consideration. ${ }^{17}$ An additional consideration for day-case endoscopy procedures and intravenous infusions is the requirement for social distancing within units. As the number of lists returns towards normal, patient numbers are generally lower per list, resulting in an increased need for theatre time, an important consideration in the recovery phase. 
In the last 14 days has the patient had SYMPTOMS suggestive of COVID-19? 1

In the last 14 days has the patient come into close CONTACT with a known or suspected case of COVID-19? 1

Does the patient's OCCUPATION mean they have been exposed to COVID-19?

Has the patient TRAVELLED and returned from a known risk area?

Screening and testing prior to endoscopy are crucial steps in the prevention of transmission of COVID-19. Table 1 shows the SCOTS criteria, which can be used to screen patients over the phone 3-7 days prior to endoscopy and can be used where testing is not available to stratify risk. Where testing is available, this should be done 1-3 days prior to the procedure and all positive or 'high-risk' (scoring $\geq 1$ SCOTS) patients deferred where possible, or endoscopy carried out at a 'hot' location specific for high-risk patients. ${ }^{17}$ In reality, the use of 'hot' location endoscopy is unlikely to be required or feasible for the majority of paediatric patients and is more amenable to an adult practice.

\section{COVID-19 risk and specific management considerations}

During the initial phase of the pandemic, there was an evolution of guidance as increased evidence emerged. It seems evident that active IBD puts adult patients at greater risk of infection with COVID-19 both within the hospital and in the community. ${ }^{34}$ Despite this, the largest dataset on over 170 children with IBD did not demonstrate any deaths associated with COVID-19 and only a single patient required ventilation. ${ }^{7}$ Within adult patients, the use of corticosteroids, but not antitumour necrosis factor (anti-TNF) agents, was associated with increased morbidity and mortality, but this was not borne out in paediatric disease. ${ }^{19}$ The BSG produced guidance to classify patients with IBD on immunosuppressive 'risk' 15 and the measures that should be followed, with some patients requiring shielding during the initial phase of the pandemic. ${ }^{22} 35$ This was also adapted by Crohn's and Colitis UK to provide a useful flowchart for patient use. ${ }^{22}$ This information was not specifically targeted to paediatric patients and the guidelines were adapted by the BSPGHAN to reflect paediatric practice. ${ }^{36}$ In many cases, clinical teams were required to discuss their patient groups and come to their own MDT decisions on patients at the highest risk. Clear government advice was made available through the initial lockdown phases for those in high-risk groups. Following the UK-wide removal of shielding for all patients in August 2020 at the time of writing, there are no paediatric patients with IBD, regardless of therapy, requiring specific COVID-19 precautions.

\section{Shielding in children}

Shielding of a small group of patients with IBD considered extremely vulnerable (steroid therapy, active disease, newly started on anti-TNF) was practised from
March to August 2020, with the need to shield ending at this point. The practicalities of implementing shielding guidance for children and families is particularly challenging and specific guidance on this is lacking. ${ }^{37}$ Recent data would suggest that many paediatric patients, even within the vulnerable 'shielding' group, are not at increased risk of severe COVID-19 and current guidance indicates that shielding will not be needed for paediatric patients with IBD in the event of a second wave, although as evidence evolves this may change. In many households, it is impossible for children to stay 1 or $2 \mathrm{~m}$ away from their parents and siblings, particularly if they are very young. Clinical teams must take this into consideration and take a pragmatic approach to advising parents on how they can reduce the risk of infection for their child while still maintaining family life. Shielding has a profound impact on the quality of life. The Royal College of Paediatrics and Child Health (RCPCH) continues to work with paediatric specialties to review and revise the need for shielding in those who were initially thought to be clinically extremely vulnerable. ${ }^{37}$

\section{Returning to school}

Many young people and parents of children with chronic conditions, such as IBD, will be anxious about schools beginning to reopen. The balance of possible risks of COVID-19, against the long-term impact of lack of schooling, is complex, with difficulties in enforcing $1-2 \mathrm{~m}$ social distancing, especially between young children and teachers. UK-wide guidance from the RCPCH, based on the most contemporary evidence, ${ }^{4}$ encourages all children with IBD to return to school. Children who were identified as 'clinically extremely vulnerable' in March 2020, and were therefore previously advised to shield, can return to school as normal at present. However, if the UK government changes shielding advice, those children who are still identified as 'clinically extremely vulnerable' may no longer be able to attend school. It is becoming increasingly clear that primary school children are much more likely to benefit from the return to school than they are to come to significant harm. ${ }^{38}$ It must be acknowledged that the practicalities of all children returning to school are complex, and there is likely to be significant anxiety for patients and families in specific scenarios. In May and September 2020, BSPGHAN produced specific guidance for returning to school, providing a framework for patients, families and clinicians to approach this topic. ${ }^{39}$ 
The indirect impact of the pandemic on children is now being felt. There is likely to be significant anxiety regarding returning to school and normal activities for some patients with IBD. It is clear that recovery planning of services and returning to normal should include the patient's opinions. ${ }^{40}$

\section{Surgery and radiological investigations}

Recent data indicated that most IBD centres across the UK maintained surgical and radiological services, even during lockdown. ${ }^{27}$ However, these were largely reduced and planned non-emergency surgery was delayed. District general hospitals had worse access to radiological investigations. The long-term sequelae of delayed surgery and the inability to identify small bowel disease, stricturing disease or complex fistulating disease will need to be carefully evaluated in order to mitigate against harm.

\section{Long-term effects on patients with IBD and mitigating strategies}

With every change to the normal running of services, there is the question of the longer-term impact on patients. Those waiting on diagnosis with milder symptoms may have their diagnostic testing deferred for a longer period. Patients with delayed diagnosis and prolonged time to initiate treatment are likely to have a direct impact on long-term care and disease management. There may be an observed decrease in suspected cases as parents put off consulting with their GPs regarding their child's symptoms. This could either be due to a misunderstanding that these services are not currently available or because of anxiety surrounding viral transmission. These misconceptions may lead to an increased number of new cases of IBD following this pandemic due to delayed diagnosis, alongside a backlog of investigations that have been put on hold during this time.

Although it is easy to look at the negative effects, the positives should be highlighted. In the future, children with a mild IBD phenotype or those who are stable and in remission may be able to switch to telephone or virtual appointments to avoid regular travel to specialist centres. Home FC testing could also be used more frequently, with results being immediately communicated to the MDT for discussion and therapeutic planning. Patients who remain stable and in remission could continue with home testing and possibly reduce their need for face-toface appointments in the long term.

\section{Planning for a second wave}

The possibility of a second wave of infection, or a continuation of the initial wave, requiring repeated local or national lockdowns, remains. Using what we have learnt from the initial wave and lockdown is vital to provide the best level of care possible to new and known paediatric patients with IBD This includes the clear need to maintain endoscopy services, prioritising assessment of acutely unwell patients, limiting the need for any form of 'shielding' and continuing with monoclonal therapy. Data on paediatric IBD in COVID-19 remain reassuring and there are positive consequences including the advancement of virtual clinics and support services, however, rigorous evaluation of outcomes, including patient opinions, will be required prior to routine implementation. A specific consideration in the event of increased COVID-19 cases will be streamlining of preendoscopy COVID-19 testing to ensure that services can continue. Additional consideration of 'cold' non-COVID hospitals to continue planned procedures may become more important.

Beyond this, formulating guidelines for future pandemics will allow structured and safe implementation of management strategies in the event that another unforeseen infectious disease sweeps the globe. This will also allow new working practices to become embedded within the NHS for years to come, using the latest technology to the benefit of patients, carers and the wider MDT. This will require extensive administrative support and careful planning.

\section{CONCLUSION}

With the forced reorganisation of multiple services across the UK, the direct and indirect impact of the COVID-19 pandemic on children with diagnosed or suspected IBD must not be overlooked. Paediatric IBD teams face ongoing difficult decisions, including which patients require treatment initiation or a change in therapy, with limited access to specific tests that are usually imperative to making these choices.

The long-term impact of COVID-19 on the running of paediatric IBD services will pose many challenges to patients and families. Despite this, the strategies implemented to continue monitoring patients during the lockdown, through minimising trips to the hospital, has the potential to revolutionise the way in which they could be managed in the future. Continuing the use of home FC testing kits, virtual appointments and email/telephone advice to support the paediatric patient with IBD group will allow for greater patient and family empowerment with fewer clinic visits. This is a complex system and the logistics of having multiple clinic modalities in the long term would require extensive planning and consideration within the MDT.

There is increasingly reassuring evidence from across the world of the lack of direct impact of COVID-19 on patients with IBD. The indirect impact of reorganisation of healthcare during the pandemic has, however, had a significant impact on patients. It is imperative professional societies continue to guide paediatric IBD teams as departments enter a 'recovery phase' in order to protect staff, patients and the wider community from the effects of this global pandemic. It is likely the lessons learnt from COVID-19, though not yet fully established, will remain far longer lasting than the pandemic itself. 
Twitter R Mark Beattie @RMBeattie50

Contributors AM and RH conceived the review. AM and JJA performed literature review and wrote the initial draft. VG, RMB and RH provided additional commentary and redrafted the manuscript. All authors reviewed the submission version.

Funding RH is supported by an NHS Research Scotland Career Researcher Fellowship. The Glasgow paediatric IBD team is supported by the Catherine McEwan Foundation. JJA is funded by an Action Medical Research training fellowship and by an ESPEN personal fellowship.

Competing interests $\mathrm{RH}$ has received consultancy fees, speaker's fees or trave support from $4 \mathrm{D}$ pharma and Nutricia. RMB has received conference and travel support from Nutricia. VG has received travel support from Tillots.

Patient consent for publication Not required.

Provenance and peer review Not commissioned; externally peer reviewed.

Data availability statement Data sharing not applicable as no datasets generated and/or analysed for this study. Not Applicable.

Open access This is an open access article distributed in accordance with the Creative Commons Attribution Non Commercial (CC BY-NC 4.0) license, which permits others to distribute, remix, adapt, build upon this work non-commercially, and license their derivative works on different terms, provided the original work is properly cited, appropriate credit is given, any changes made indicated, and the use is non-commercial. See: http://creativecommons.org/licenses/by-nc/4.0/.

ORCID iDs

Abbie Maclean http://orcid.org/0000-0001-9683-228X

R Mark Beattie http://orcid.org/0000-0003-4721-0577

\section{REFERENCES}

1 CROHN'S AND COLITIS UK. Children and young people with IBD, 2017. Available: https://www.crohnsandcolitis.org.uk/about-crohnsand-colitis/publications/children-young-people-with-ibd-a-guide-forschools

2 Ashton JJ, Cullen M, Afzal NA, et al. Is the incidence of paediatric inflammatory bowel disease still increasing? Arch Dis Child 2018;103:archdischild-2018-315038.

3 Ashton JJ, Batra A, Coelho TAF, et al. Challenges in chronic paediatric disease during the COVID-19 pandemic: diagnosis and management of inflammatory bowel disease in children. Arch Dis Child 2020;105:706.

4 Munro APS, Faust SN. Children are not COVID-19 super spreaders: time to go back to school. Arch Dis Child 2020;105:618-9.

5 Turner D, Huang Y, Martín-de-Carpi J, et al. Corona virus disease 2019 and paediatric inflammatory bowel diseases: global experience and provisional guidance (March 2020) from the paediatric IBD Porto group of European Society of paediatric gastroenterology, hepatology, and nutrition. J Pediatr Gastroenterol Nutr 2020;70:727-33.

6 Norsa L, Indriolo A, Sansotta N, et al. Uneventful course in patients with inflammatory bowel disease during the severe acute respiratory syndrome coronavirus 2 outbreak in northern Italy. Gastroenterology 2020;159:371-2

7 Brenner EJ, Ungaro RC, Colombel JF, et al. SECURE-IBD Database Public Data Update. Current Data, 2020. Available: https://covidibd. org/current-data/

8 Levine A, Koletzko S, Turner D, et al. ESPGHAN revised Porto criteria for the diagnosis of inflammatory bowel disease in children and adolescents. J Pediatr Gastroenterol Nutr 2014;58:795-806.

9 Kennedy NA, Hansen R, Younge L, et al. Organisational changes and challenges for inflammatory bowel disease services in the UK during the COVID-19 pandemic. Frontline Gastroenterol 2020;11:343-50.

10 Lee D-W, Koo JS, Choe JW, et al. Diagnostic delay in inflammatory bowel disease increases the risk of intestinal surgery. World $\mathrm{J}$ Gastroenterol 2017:23:6474-81.

11 NICE. Faecal calprotectin diagnostic tests for inflammatory diseases of the bowel. Diagnostic guidance [DG11], 2013. Available: https:// www.nice.org.uk/guidance/dg11/chapter/4-The-diagnostic-tests [Accessed 31 May 2020]

12 ESPGHAN. GI endoscopy in children and Covid-19 pandemic, 2020. Available: http://www.espghan.org/societal-papers/covid19-informational-statements/?jumpurl=uploads $\% 2 F m e d i a \%$ 2FESPGHAN GI endoscopy and COVID 19 Pandemic.pdf\& juSecure $=1 \&$ mimeType $=$ application $\% 2 F p d f \& l o c a t i o n D a t a=683 \%$ 3Att content\%3A1558\&juHash=f089d396c04ddcde96ea2c427071 e2ca8de28ff6 [Accessed 16 Apr 2020].
13 British Society of Gastroenterology. Endoscopy activity and COVID-19: BSG and JAG guidance. Available: https://www.bsg. org.uk/covid-19-advice/endoscopy-activity-and-covid-19-bsgand-jag-guidance/?utm source=Members\&utm campaign= ffd002b62b-EMAIL_CAMPAIGN_2020_02_13_03_21_COPY_01\& utm_medium =email\&utm_term $=0$ _be5fefa54d-ffd002b62b-\&mc cid=ffd002b62b\&mc eid=\%5bUNIQID\%5d [Accessed $21 \mathrm{Apr}$ 2020].

14 British Society of Gastroenterology. BSG Multi-society guidance on further recovery of endoscopy services during the post-pandemic phase of COVID-19, 2020. Available: https://www.bsg.org.uk/ covid-19-advice/bsg-multi-society-guidance-on-further-recoveryof-endoscopy-services-during-the-post-pandemic-phase-of-covid19/?utm_source=The+British+Society+of+Gastroenterology\& utm campaign=e4ad9ab40a-EMAIL CAMPAIGN $202008 \quad 14$ 03_30_COPY_01\&utm_medium =email\&utm_term=0_be $5 \mathrm{fefa} 5 \overline{4} \mathrm{~d}$ e4ad9ab40a-45482573\&mc cid=e4ad9ab40a\&mc eid=0f582e9cf0 [Accessed 31 Aug 2020].

15 British Society of Gastroenterology. BSG expanded consensus advice for the management of IBD during the COVID-19 pandemic. Available: https://www.bsg.org.uk/covid-19-advice/bsg-advice-formanagement-of-inflammatory-bowel-diseases-during-the-covid-19pandemic/ [Accessed 29 Apr 2020].

16 Zhang Y, Chen C, Zhu S, et al. Isolation of 2019-nCoV from a stool specimen of a laboratory-confirmed case of the coronavirus disease 2019 (COVID-19). China CDC Weekly 2020;2:123-4.

17 May B. BSPGHAN consensus statement on paediatric endoscopy recovery and restoration during Covid-19 pandemic (May 10th 2020), 2020. Available: https://bspghan.org.uk/wp-content/uploads/ 2020/05/BSPGHAN-statement-on-endoscopy-recovery-May-10th2020.pdf [Accessed 16 Jun 2020].

18 Bezzio C, Saibeni S, Variola A, et al. Outcomes of COVID-19 in 79 patients with IBD in Italy: an IG-IBD study. Gut 2020;69:1213-7.

19 Brenner EJ, Ungaro RC, Gearry RB, et al. Corticosteroids, but not TNF antagonists, are associated with adverse COVID-19 outcomes in patients with inflammatory bowel diseases: results from an international registry. Gastroenterology 2020;159:481-91.

20 Lamb CA, Kennedy NA, Raine T, et al. British Society of gastroenterology consensus guidelines on the management of inflammatory bowel disease in adults. Gut 2019;68:s1-106.

21 Wisniewski A, Kirchgesner J, Seksik P, et al. Increased incidence of systemic serious viral infections in patients with inflammatory bowel disease associates with active disease and use of thiopurines. United European Gastroenterol J 2020;8:303-13.

22 Crohn's and Colitis UK. Coronavirus (COVID-19): What is the risk to those with Crohn's and Colitis? Decision Tree Version 5, 2020. Available: http://s3-eu-west-1.amazonaws.com/files. crohnsandcolitis.org.uk/decision_tree_v5.pdf [Accessed $26 \mathrm{Apr}$ 2020].

23 Din S, Kent A, Pollok RC, et al. Adaptations to the British Society of Gastroenterology guidelines on the management of acute severe UC in the context of the COVID-19 pandemic: a RAND appropriateness panel. Gut 2020;69:gutjnl-2020-321927.

24 Hansen R, Meade S, Beattie RM, et al. Adaptations to the current ECCO/ESPGHAN guidelines on the management of paediatric acute severe colitis in the context of the COVID-19 pandemic: a RAND appropriateness panel. Gut 2020. doi:10.1136/gutjnl-2020-322449. [Epub ahead of print: 01 Sep 2020].

25 Kennedy NA, Jones G-R, Lamb CA, et al. British Society of gastroenterology guidance for management of inflammatory bowel disease during the COVID-19 pandemic. Gut 2020;69:984-90.

26 Cambridge University Hospitals NHS Foundation Trust. Shared care guidelines: thiopurines for paediatric inflammatory bowel disease, 2020. Available: https://www.cambridgeshireandpeterboroughccg nhs.uk/easysiteweb/getresource.axd?assetid=10937\&type $=0 \&$ servicetype=1

27 Ashton JJ, Kammermeier J, Spray C, et al. Impact of COVID-19 on diagnosis and management of paediatric inflammatory bowel disease during lockdown: a UK nationwide study. Arch Dis Child 2020. doi:10.1136/archdischild-2020-319751. [Epub ahead of print: 30 Jul 2020]

28 Galway N, Stewart G, Maskery J, et al. Fifteen-minute consultation: a practical approach to remote consultations for paediatric patients during the COVID-19 pandemic. Arch Dis Child Educ Pract Ed 2020. doi:10.1136/archdischild-2020-320000. [Epub ahead of print: 24 Aug 2020]

29 Wherton J, Shaw S, Papoutsi C, et al. Guidance on the introduction and use of video consultations during COVID-19: important lessons from qualitative research. BMJ Leader 2020;4:120-3.

30 Vinding $\mathrm{KK}$, Elsberg $\mathrm{H}$, Thorkilgaard $\mathrm{T}$, et al. Fecal calprotectin measured by patients at home using smartphones--a new clinical 
tool in monitoring patients with inflammatory bowel disease. Inflamm Bowel Dis 2016;22:336-44.

31 Heida A, Knol M, Kobold AM, et al. Agreement between home-based measurement of stool calprotectin and ELISA results for monitoring inflammatory bowel disease activity. Clin Gastroenterol Hepatol 2017;15:1742-9.

32 Piekkala M, Alfthan H, Merras-Salmio L, et al. Fecal calprotectin test performed at home: a prospective study of pediatric patients with inflammatory bowel disease. J Pediatr Gastroenterol Nutr 2018;66:926-31.

33 British Society of Gastroenterology. COVID19 guidance and advice, 2020. Available: [Accessed 20/06/20]. Available from: https://www. bsg.org.uk/covid-19-advice/

34 Zhou F, Yu T, Du R, et al. Clinical course and risk factors for mortality of adult inpatients with COVID-19 in Wuhan, China: a retrospective cohort study. Lancet 2020;395:1054-62.

35 Public Health England. Guidance on shielding and protecting people who are clinically extremely vulnerable from COVID-19, 2020. Available: https://www.gov.uk/government/publications/guidanceon-shielding-and-protecting-extremely-vulnerable-personsfrom-covid-19/guidance-on-shielding-and-protecting-extremelyvulnerable-persons-from-covid-19\#staying-at-home-and-shielding

36 BSPGHAN IBD Working Group. British Society of paediatric gastroenterology, hepatology and nutrition (BSPGHAN) coronavirus (SARS-CoV-2) and COVID-19 in children with IBD. position statement: management of PIBD during the SARS-CoV-2 pandemic, 2020. Available: https://bspghan.org.uk/wp-content/uploads/2020/ 04/COVID_IBDWG_HCP.pdf

37 Royal College of Paediatrics and Child Health (RCPCH). COVID19'shielding' advice for children and young people, 2020. Available: https://www.rcpch.ac.uk/resources/covid-19-shielding-guidancechildren-young-people [Accessed 28 Jun 2020].

38 Royal College of Paediatrics and Child Health (RCPCH). COVID-19talking to children and families about returning to school: guiding principles, 2020. Available: https://www.rcpch.ac.uk/resources/ covid-19-talking-children-families-about-returning-school-guidingprinciples\#england [Accessed 28 May 2020].

39 BSPGHAN IBD Working Group. British Society of paediatric gastroenterology, hepatology and nutrition (BSPGHAN) coronavirus (SARS-CoV-2) and COVID-19 in children with IBD. position statement: Guidence for Returnig to school, 2020. Available: https://bspghan.org. uk/wp-content/uploads/2020/05/COVID_IBDWG_HCP_RTS.pdf

40 Larcher V, Dittborn M, Linthicum J, et al. Young people's views on their role in the COVID-19 pandemic and society's recovery from it. Arch Dis Child 2020;1669:archdischild-2020-320040.

41 Hayee Bu'Hussain, Thoufeeq M, Rees CJ, et al. Safely restarting Gl endoscopy in the era of COVID-19. Gut 2020. doi:10.1136/ gutjnl-2020-321688. [Epub ahead of print: 05 Jun 2020]. 